\title{
Efeito da Restrição Alimentar como Redutor do Poder Poluente dos Dejetos de Suínos ${ }^{1}$ Simara Márcia Marcato², Gustavo Júlio Mello Monteiro de Lima ${ }^{3}$
}

\begin{abstract}
RESUMO - Com o objetivo de avaliar o efeito da restrição alimentar sobre a excreção de minerais nas fezes de suínos, foram utilizados 48 machos castrados com peso inicial de 41,92 $\pm 0,21 \mathrm{~kg}$, distribuídos em delineamento de blocos casualizados, com três tratamentos $(\mathrm{T} 1=$ alimentação à vontade; $\mathrm{T} 2=95 \%$ do consumo diário apresentado por T1; e T3=90\% do consumo diário apresentado por T1) e 16 repetições. Os animais permaneceram durante 21 dias em adaptação aos tratamentos em baias coletivas e gaiolas de estudos metabólicos. As coletas de urina e fezes foram realizadas durante dois dias, utilizando-se 20 g de partículas de plástico colorido como marcador fecal. Houve redução de 8,54\% no consumo diário de ração dos animais do T3, acarretando em decréscimo em torno de $9,65 \%$ excreção de matéria mineral nas fezes, quando comparado com o consumo ad libitum (T1). Todos os macrominerais, com exceção do magnésio, sofreram redução significativa no conteúdo fecal com o aumento da restrição alimentar. Os teores de cálcio e potássio das fezes representaram cerca de $29 \%$ da matéria mineral excretada pelas fezes dos animais e foram reduzidos significativamente com o emprego da restrição alimentar. Para todos os microminerais, as relações entre as quantidades excretadas e as quantidades consumidas foram iguais ou superiores a 86,60\%, indicando que os animais apresentaram baixa eficiência de retenção desses nutrientes. Concluiu-se que a restrição alimentar de suínos em fase de terminação acarreta redução da quantidade de matéria seca e da maioria dos minerais excretados.
\end{abstract}

Palavras-chave: cobre, fezes, fósforo, minerais, nitrogênio, urina, zinco

\section{Feed Restriction as an Alternative to Reduce Environmental Impact of Swine Waste}

ABSTRACT - With the objective to evaluate the effect of feed restriction on fecal mineral content of finishing swine, fortyeight barrows, with initial weight of $41.92 \pm 0.27 \mathrm{~kg}$ were assigned to a randomized experimental block design. Treatments were: $\mathrm{T} 1=$ ad libitum feeding; T2=95\% T1 feed intake; and T3 $=90 \% \mathrm{~T} 1$ feed intake and 16 replications. Animals were kept during 21 days in adaptation period to the treatments in collective pens and metabolism cages. Urine and fecal collection was performed during two days, using $20 \mathrm{~g}$ of colored plastic particles as fecal markers. There was a reduction of $8.54 \%$ in the daily feed consumption of the diet in T3 animals, causing a decrease close to $9.65 \%$ in fecal mineral content, as compared to ad libitum consumption (T1). All macro minerals, except for magnesium, showed significant reduction in the fecal content with the increase of feed restriction. Calcium and potassium fecal content represented about $29 \%$ of the excreted mineral matter of the animals and both were significantly reduced with the use of feed restriction. For all micro minerals, the relations between excreted amount and consumed amount were equal or higher than $86.60 \%$, indicating that the animals showed a low retention efficiency of these nutrients. In conclusion, feed restriction in finishing phase of swine cause reduction in the amount of dry matter and almost all minerals excreted. Therefore, the use of this practice can contribute to reduce pollution problems of swine manure.

Key Words: minerals, nitrogen, phosphorus, copper, zinc, feces, urine

\section{Introdução}

A suinocultura é um dos setores da pecuária brasileira que mais se desenvolve, tendo apresentado crescimento médio de $15 \%$ ao ano no último quinquênio (Bohrer, 2003). Este grande desenvolvimento, embora tenha proporcionado grandes benefícios à sociedade, também gerou poluição ambiental, em decorrência da quantidade de dejetos produzidos pelos animais.
A alta concentração de suínos nas regiões Norte do Rio Grande do Sul e Oeste de Santa Catarina e Paraná promoveu desequilíbrio ecológico, causando a contaminação das fontes de água, de forma que, na Região Oeste de Santa Catarina, cerca de $85 \%$ dos mananciais de água foram contaminados por coliformes fecais (Oliveira et al., 1993). Há casos, como o do o rio Lajeado do São José, que abastece a cidade de Chapecó, em que as águas contêm, em média,

\footnotetext{
${ }^{1}$ Parte da Dissertação da primeira autora para obtenção do título de Mestre - UFPel.

${ }^{2}$ Msc em Zootecnia, E.mail: simaramm@yahoo.com.br.

${ }^{3}$ PhD. em Nutrição de Suínos, Pesquisador da Embrapa Suínos e Aves, Concórdia, SC.
} 
4000 coliformes fecais por litro (Guivant, 1996). Neste rio, quando há ocorrências de chuvas, o nível médio de coliformes fecais se eleva para 14.000/L, impossibilitando o seu uso para consumo humano e animal.

O excesso de produção de dejetos animais pode acarretar poluição do ar e do solo. A contaminação do ar ocorre com a evaporação de compostos voláteis dos dejetos que causam prejuízos ao bem-estar humano e animal (Voolburg, 1991; Cromwell et. al., 1996). Tem-se constatado que suínos expostos a altos níveis de amônia, por um curto período de tempo, apresentam redução no ganho de peso (Anderson et al., 1994; Cole et al., 1996).

Os dejetos de suínos contém micronutrientes, como o $\mathrm{Zn}, \mathrm{Mn}, \mathrm{Cu}$ e Fe, que, em doses elevadas ou aplicados continuamente, podem ser tóxicos às plantas e apresentam riscos de contaminação do solo (Perdomo, 1996).

Várias pesquisas na área de nutrição animal tem sido realizadas com o objetivo de redução do poder poluente causado pelos dejetos dos suínos (Lenis, 1989; Henry \& Dourmad, 1992; Quinou et al., 1994). Em alguns estudos, o aumento da digestibilidade da matéria seca da dieta, de $85 \%$ para $90 \%$, tem promovido queda de $30 \%$, aproximadamente, na excreção de matéria seca pelas fezes (Inborr 1992; Perdomo, 1996). A excreção de $\mathrm{N}$ pode ser reduzida em até $35 \%$ quando suínos são alimentados com dietas contendo $15 \%$ de proteína bruta suplementadas com aminoácidos, em comparação com animais alimentados com dietas contendo $18 \%$ de PB, sem suplementação de aminoácidos (Cromwell et al., 1996).

O uso da restrição alimentar em suínos tem ocorrido em muitos países com o intuito de melhorar a eficiência alimentar dos animais, a partir do melhor aproveitamento dos nutrientes e da redução do desperdício de alimento. Com esta prática, tem-se verificado também melhoria na qualidade de carcaça dos suínos, comprovada pelo aumento da porcentagem de carne e pela redução de gordura na carcaça (Campbell \& King, 1982; Bellaver, 1992).

Uma vez que a restrição alimentar dos suínos pode melhorar a eficiência alimentar, pode haver concomitante redução da quantidade de dejetos e de nutrientes excretados. Portanto, este estudo foi conduzido para avaliar se o emprego da restrição alimentar pode se constituir em um manejo benéfico para redução da excreção total e de minerais pelos dejetos produzidos por suínos.

\section{Material e Métodos}

O experimento foi conduzido nas instalações experimentais da Embrapa Suínos e Aves, situada no município de Concórdia, em Santa Catarina. Foram utilizados 48 machos castrados, Landrace x Large White x Duroc, com peso inicial de $41,92 \pm 0,21 \mathrm{~kg}$ e peso final de $58,59 \pm 0,26 \mathrm{~kg}$, filhos de mesmo cachaço e escolhidos conforme o peso e a idade. Os animais foram distribuídos nas unidades experimentais segundo um delineamento em blocos ao acaso, com 16 repetições por tratamento.

Calculou-se uma dieta basal (Tabela 1) para atender ou exceder as exigências do NRC (1998).

Os tratamentos consistiram no fornecimento desta dieta aos animais em diferentes quantidades: T1=alimentação à vontade; T2=95\% do consumo diário apresentado por T1; e T3=90\% do consumo diário apresentado por $\mathrm{T} 1$.

Na Tabela 2, são apresentados os níveis analisados de cada elemento mineral estudado presentes na dieta basal.

Os animais foram alojados durante 14 dias em baias coletivas, recebendo ração à vontade. Após este período, foram transferidos para gaiolas de estudos metabólicos, mantidas em sala com temperatura controlada, em torno de $22^{\circ} \mathrm{C}$, onde permaneceram por sete dias para adaptação às gaiolas e mais dois dias, para coleta de fezes e urina.

Durante o período pré-experimental nas baias e gaiolas, os animais receberam a ração experimental para prévia adaptação, quando também foi acompanhado o consumo de animais, para determinação da restrição alimentar.

Durante o período experimental, a ração foi fornecida aos animais em duas refeições diárias (às 8 h30 e 14h30) e a água, à vontade.

Para determinação do início e final do período de coleta, foi adicionado à primeira refeição dos animais ao $7^{\circ}$ e $9^{\circ}$ dias, quando se encontravam nas gaiolas de estudos metabólicos $20 \mathrm{~g}$ de plástico colorido (partículas de, no máximo, $0,7 \times 0,7 \mathrm{~cm}$ ). As fezes foram coletadas em bandejas de aço inoxidável, adotandose o método de coleta total de fezes, e a urina foi filtrada e recolhida em baldes plásticos contendo 20 ml de ácido clorídrico 1:1, para evitar perdas de nitrogênio e proliferação de bactérias. Diariamente, durante o período de coleta de excretas, as fezes foram pesadas e o volume de urina foi medido indivi- 
Tabela 1 - Composição percentual e calculada da dieta basal

Table 1 - Percent and calculated composition of the basal diet

\begin{tabular}{|c|c|}
\hline $\begin{array}{l}\text { Ingrediente } \\
\text { Ingredient }\end{array}$ & $(\%)$ \\
\hline Milho & 74,90 \\
\hline Corn & \\
\hline Farelo de soja & 19,63 \\
\hline Soybean meal & \\
\hline Óleo de soja & 2,27 \\
\hline Soybean oil & \\
\hline Calcário & 1,40 \\
\hline Limestone & \\
\hline Fosfato bicálcico & 1,28 \\
\hline Dicalcium phosphate & \\
\hline DL-metionina & 0,03 \\
\hline DL-methionine & \\
\hline Colina & 0,05 \\
\hline Choline & \\
\hline Sal & 0,22 \\
\hline Salt & \\
\hline Premix vitamínico ${ }^{1}$ & 0,10 \\
\hline Vitamin premix & \\
\hline Premix mineral $^{2}$ & 0,08 \\
\hline Mineral premix & \\
\hline BHT & 0,01 \\
\hline Antibiótico & 0,03 \\
\hline Antibiotic & \\
\hline
\end{tabular}

Total 100,00

Composição calculada

Calculated composition

Proteína bruta, \%

Crude protein

Energia metabolizável, $\mathrm{kcal} / \mathrm{kg}$

Metabolizable energy

Cálcio, \%

0,80

Calcium

Fósforo total, \%

Total phosphorus

Fósforo disponível, \% $\quad 0,33$

Available phosphorus

Lisina, \%

0,70

Lysine

Metionina + Cistina, $\%$

Methionine+ Cystine

Triptofano, \%

Tryptophan

Treonina, \%

Threonine

1,2 Quantidades $/ \mathrm{kg}$ de dieta (Content $/ \mathrm{kg}$ of diet): $0,22 \mathrm{mg} \mathrm{Se}$, 2500 UI vit. A, 1000 UI vit. D3, $17 \mathrm{mg}$ vit. $E, 1,05 \mathrm{mg}$ vit. $K, 1,5 \mathrm{mg}$ vit. $B 1,2,55 \mathrm{mg}$ vit. $B 2,1,8 \mathrm{mg}$ vit. B6, $12 \mathrm{mcg}$ vit. B12, $12,5 \mathrm{mg}$ de ácido nicotínico (nicotinic acid), $8,1 \mathrm{mg}$ de ácido pantotênico (pantothenic acid), 0,66 mg de ácido fólico (folic acid), 0,11 mg de biotina (biotin), 53,28 mg Fe, 66,64 mg Cu, 16,32 mg Mn, 41,04 mg $\mathrm{Zn} \mathrm{e} 0,46 \mathrm{mg} \mathrm{I}$.

dualmente, coletando-se uma alíquota de $10 \%$ do volume total excretado. Todas as amostras foram armazenadas a $3^{\circ} \mathrm{C}$, realizando-se, posteriormente, a homogeneização das fezes, ao final do experimento,
Tabela 2 - Composição em matéria seca e mineral da dieta basal

Table 2 - Chemical composition in dry matter and ash of the basal diet

\begin{tabular}{lc}
\hline Matéria seca (\%) & 88,1 \\
$\begin{array}{l}\text { Dry matter } \\
\text { Matéria mineral (\%) } \\
\text { Ash }\end{array}$ & 4,73 \\
Cálcio (\%) & 0,79 \\
Calcium & \\
Fósforo total (\%) & 0,50 \\
Total phosphorus & \\
Magnésio (\%) & 0,14 \\
Magnesium & \\
Sódio (\%) & 0,05 \\
Sodium & \\
Potássio (\%) & 0,69 \\
Potassium & \\
Nitrogênio (\%) & 2,40 \\
Nitrogen & \\
Cobre (mg/kg) & \\
Copper & 7,45 \\
Ferro (mg/kg) & \\
Iron & 289,49 \\
Manganês (mg/kg) & 19,21 \\
Manganese & \\
Zinco (mg/kg) & 126,06 \\
Zinc & \\
\hline
\end{tabular}

em um homogeneizador de aço inoxidável, retirandose uma amostra final de, aproximadamente, $300 \mathrm{~g}$. As amostras de fezes foram secas em estufa de ventilação forçada a $65^{\circ} \mathrm{C}$, por 48 horas, sendo, seqüencialmente, moídas.

As análises laboratoriais dos ingredientes, das dietas, fezes e da urina foram realizadas segundo Silva (1990). Na dita basal e nas fezes, foram analisados os teores de matéria seca, matéria mineral, nitrogênio, fósforo, cálcio, cobre, zinco, ferro, potássio e sódio. Também foram determinados o consumo diário de ração, a quantidade de fezes excretadas e o volume e teor de nitrogênio na urina.

O balanço de cada mineral estudado foi calculado ajustando-se o consumo de ração e a excreção diária de fezes para $100 \%$ de matéria seca e utilizando-se a seguinte fórmula genérica: $\mathrm{Y}=(\mathrm{E} / \mathrm{I})$ 100; em que: $\mathrm{Y}=\%$ de mineral excretado; $\mathrm{E}=$ quantidade de mineral excretado ( $\mathrm{g} / \mathrm{dia}$ ) e $\mathrm{I}=$ quantidade de mineral ingerido (g/dia). No caso do cálculo do percentual de nitrogênio excretado, foi considerada a quantidade diária de $\mathrm{N}$ excretado na urina, além do $\mathrm{N}$ fecal.

Os resultados foram analisados por meio da análises de variância e covariância, realizando-se comparações de médias, duas a duas, pelo teste $\mathrm{T}$, quando 
o valor de F da ANOVA foi significativo, considerando-se a hipótese unilateral. Foram empregados os procedimentos UNIVARIATE e GLS (SAS, 2001), para realização das análises descritivas, de variância e covariância.

\section{Resultados e Discussão}

Detectou-se por meio da análise descritiva dos dados, seguida de análise de variância, que o valor do teor de magnésio das fezes de um animal do T3 alterava o tipo de resposta dos tratamentos, constituindo-se, portanto, em outlier. Optou-se, então, pela eliminação desse valor, que foi o único dado não considerado na análise estatística.

A variável peso do animal não foi significativa $(\mathrm{P}>0,15)$ em nenhuma das análises realizadas, sendo portanto, retirada do modelo principal.

O consumo médio de ração dos animais e as quantidades médias de fezes excretadas durante o período de coleta de fezes e urina são apresentados na Tabela 3. Os animais designados para receber $95 \mathrm{e}$ $90 \%$ da quantidade de ração à vontade acabaram consumindo 98,40 e 91,46\%, principalmente, em razão de o consumo ter sido calculado com base no período em que os animais estavam alojados em grupos, nas baias. Ao serem transferidos para as gaiolas, os animais que recebiam ração à vontade apresentaram menor consumo, provavelmente em decorrência da redução das necessidades para permanência nas gaiolas e da eliminação da competitividade com outros animais para adquirir alimento.

Como os tratamentos foram definidos com base na quantidade de alimento consumido diariamente pelos animais, não se justificaria a análise estatística das variáveis consumo de ração e consumo dos diversos nutrientes estudados, entretanto, em virtude de o nível de restrição alimentar ter sido inferior ao planejado, realizou-se a análise estatística dessas variáveis. As médias absolutas das variáveis de consumo

Tabela 3 - Efeito da restrição alimentar sobre o consumo de ração e a quantidade de fezes excretada e relação dessas variáveis, com base na matéria natural e na matéria seca

Table 3 - Effect of feed restriction on feed consumption, amount of excreted feces and relation of these variables, in natural and dry matter basis

\begin{tabular}{|c|c|c|c|c|c|c|}
\hline \multirow[t]{2}{*}{$\begin{array}{l}\text { Parâmetro } \\
\text { Parameter }\end{array}$} & \multicolumn{3}{|c|}{$\begin{array}{c}\text { Tratamento } \\
\text { Treatment }\end{array}$} & \multirow[b]{2}{*}{ EPM } & \multirow[b]{2}{*}{$\mathrm{P}=\mathrm{F}$} & \multirow[b]{2}{*}{$\mathrm{P}=\mathrm{t}$} \\
\hline & $\mathrm{T} 1$ & $\mathrm{~T} 2$ & T3 & & & \\
\hline \multicolumn{7}{|l|}{ Matéria natural } \\
\hline $\begin{array}{l}\text { Consumo de ração, g/d } \\
\text { Feed intake }\end{array}$ & $1.635,99 \mathrm{a}$ & $1.609,77 \mathrm{a}$ & $1.496,33 \mathrm{~b}$ & 30,76 & 0,003 & 0,01 \\
\hline $\begin{array}{l}\text { Fezes excretadas, g/d } \\
\text { Excreted feces }\end{array}$ & $1.233,30$ & $1.174,56$ & $1.092,94$ & 71,70 & 0,39 & \\
\hline $\begin{array}{l}\text { Relação excretado: consumido (\%) } \\
\text { Excreted:intake ratio }\end{array}$ & 37,29 & 36,55 & 36,51 & 2,09 & 0,96 & \\
\hline $\begin{array}{l}\text { Matéria seca } \\
\text { Dry matter }\end{array}$ & & & & & & \\
\hline $\begin{array}{l}\text { Consumo de ração, g/d } \\
\text { Feed intake }\end{array}$ & $1.441,31 \mathrm{a}$ & $1.418,21 \mathrm{a}$ & $1.318,27 \mathrm{~b}$ & 27,10 & 0,003 & 0,01 \\
\hline $\begin{array}{l}\text { Fezes excretada, } \mathrm{g} / \mathrm{d} \\
\text { Excreted feces }\end{array}$ & $200,07 \mathrm{a}$ & $180,93 \mathrm{~b}$ & $181,66 \mathrm{~b}$ & 9,42 & 0,13 & 0,17 \\
\hline $\begin{array}{l}\text { Relação excretado: consumido (\%) } \\
\text { Excreted:intake ratio }\end{array}$ & 13,77 & 12,77 & 13,78 & 0,60 & 0,41 & \\
\hline
\end{tabular}

Nível de restrição alimentar, \%

Level of feed restriction

\begin{tabular}{|c|c|c|c|}
\hline Planejado & 100,00 & 95,00 & 90,00 \\
\hline Expected & & & \\
\hline $\begin{array}{l}\text { Observado } \\
\text { Observed }\end{array}$ & 100,00 & 98,40 & 91,46 \\
\hline
\end{tabular}

a,b,c Médias na mesma linha, seguidas por letras diferentes, são diferentes $(P<0,15)$ pelo teste $F$.

EPM Erro-padrão da média.

a,b,c Means whithin a row, followed by different letters, are different $(P<.15)$ by $F$ test.

EPM Standard error of mean. 
diário de cada nutriente estudado decresceram com o aumento da restrição alimentar, conforme desejado. Porém, houve diferença significativa $(\mathrm{P}=0,01)$ apenas para o maior nível de restrição (T3) em comparação aos demais níveis de alimentação.

Embora o emprego da restrição tenha reduzido a quantidade absoluta de fezes excretadas, houve efeito significativo da restrição alimentar apenas quando se calculou essa variável com base na matéria seca $(\mathrm{P}=0,13)$. Entretanto, a quantidade de fezes produzidas não variou entre os níveis de restrição alimentar $(\mathrm{P}=0,96)$. Esses resultados demonstram a importância de se estudar balanços de elementos com base na matéria seca, pois a excreção de água, seja na forma de urina ou fezes, varia consideravelmente entre animais como resultado do efeito de diversos fatores fisiológicos individuais e ambientais.

Alguns autores (Kolb, 1976; Clanton et al., 1991; Oliveira, 1994; Belli Filho, 1995) afirmam que a quantidade de dejetos de suínos é influenciada pela quantidade, composição e forma física (sólido, pastoso e líquido) do alimento, pelo sexo, peso vivo, pelas atividades desenvolvidas, pela temperatura, umidade, pelo nível de fibra e proteína da ração, além da quantidade de água ingerida pelos animais. Para Honeyman (1992), a água é o maior constituinte dos dejetos e apresenta variação de 85 a $95 \%$, reduzindo a concentração de nutrientes e aumentando o volume excretado, o que acarreta dificuldades no armazenamento e transporte desses dejetos.

Quando se estudou a relação entre quantidades de fezes excretadas e o consumo de ração, verificou-se que as taxas foram similares, independentemente do nível de alimentação imposto aos animais, considerando-se tanto os dados com base na matéria natural $(\mathrm{P}=0,96)$ como na matéria seca $(\mathrm{P}=0,41)$, o que indica que a digestibilidade da ração não foi afetada pelo consumo. Observou-se que os valores médios das relações quantidade de fezes excretadas e consumo de ração foram de 36,78 e $13,44 \%$ para valores na matéria natural e seca, respectivamente.

Nas Tabelas 4 e 5, são apresentadas as médias de consumo, excreção e da relação excretado:consumido dos minerais na matéria seca. Houve redução significativa $(\mathrm{P}=0,09)$ na excreção de $\mathrm{P}$ quando se restringiu a quantidade de alimento fornecido aos animais, em torno de 9,7 e 10,4\%, para restrições de 98,40 e de $91,46 \%$, respectivamente.

Verificou-se que, tanto nas fezes como na urina, houve redução da excreção de nitrogênio com o aumento da restrição alimentar. Essa redução foi significativa apenas quando se comparou os animais do maior nível de restrição com aqueles que receberam ração à vontade. Por outro lado, a taxa de redução de $\mathrm{N}$ excretado pelas fezes $(9,09$ e $12,41 \%)$ foi maior que pela urina $(2,05$ e $7,89 \%)$ para o menor e maior nível de restrição alimentar, respectivamente, indicando que a redução de $\mathrm{N}$ pela urina foi similar à redução no fornecimento de alimento aos animais, mas os efeitos sobre a redução no $\mathrm{N}$ fecal aconteceram com maior intensidade. Mesmo com a redução de consumo de $\mathrm{N}$, observou-se que o $\mathrm{N}$ absorvido permitiu o suficiente para uma nutrição adequada, pois não houve desbalanceamento de aminoácidos, caso contrário, o nível de nitrogênio na urina teria sido aumentado (Brown \& Cline, 1974).

Em xperimento realizado com suínos em gaiolas de estudos metabólicos, Brown \& Cline (1974) constataram que a adição de $0,5 \%$ de lisina $\mathrm{HCl}$ na dieta contendo $16 \%$ de proteína bruta proporcionou redução significativa $(\mathrm{P}<0,01)$ na quantidade de uréia excretada via urina $(27,27 \%)$, quando comparado aos animais que não receberam suplementação de lisina $\mathrm{HCl}$ na dieta.

Quiniou et al. (1995) verificaram que o nitrogênio fecal não foi significativamente afetado pela composição da dieta, mas o nitrogênio urinário foi maior $(\mathrm{P}<0,01)$ nos suínos que receberam dieta com $24,3 \%$ de proteína bruta do que os animais que receberam $17,7 \%$ de proteína bruta $(24,8$ vs $19,5 \mathrm{~g} / \mathrm{dia})$.

Se de um lado a redução do fornecimento de $\mathrm{N}$ dietético promove maior absorção de compostos nitrogenados no intestino, reduzindo a excreção fecal, os resultados obtidos com a análise de $\mathrm{N}$ na urina sugerem que a utilização de $\mathrm{N}$ em nível metabólico é aumentada com a restrição, promovendo os efeitos benéficos sobre a carcaça, principalmente reduzindo a deposição de gordura (Leymaster \& Mersmann, 1994).

Latimier \& Dourmand (1993), Quiniou et al. (1994), Bridges et al. (1995) e Cromwell et al. (1996) observaram que o $\mathrm{N}$ fecal foi reduzido com o decréscimo do conteúdo de proteína da dieta. Segundo Lenis (1989), Henry \& Dourmand (1992) e Silva et al. (1993), a redução do conteúdo de proteína da dieta contribui para o catabolismo do excesso de aminoácidos.

A quantidade média de $\mathrm{N}$ excretado nas fezes foi de 5,31 g/dia e, na urina, de 15,06 g/dia, confirmando que a via urinária é a principal forma de excreção de 
Tabela 4 - Efeito da restrição alimentar sobre os valores médios de consumo, excreção e relação excretado:consumido de matéria mineral, fósforo, nitrogênio, cálcio, magnésio, sódio e potássio, na matéria seca

Table 4 - Effect of feed restriction on averages of consumption, excretion and excreted:intake relation of mineral matter, phosphorus, nitrogen, calcium, magnesium, sodium and potassium, in dry matter

\begin{tabular}{|c|c|c|c|c|c|c|}
\hline \multirow[b]{2}{*}{$\begin{array}{l}\text { Parâmetro } \\
\text { Parameter }\end{array}$} & \multicolumn{3}{|c|}{$\begin{array}{c}\text { Tratamento } \\
\text { Treatment } \\
\end{array}$} & \multirow[b]{2}{*}{ EPM } & \multirow[b]{2}{*}{$\mathrm{P}=\mathrm{F}$} & \multirow[b]{2}{*}{$\mathrm{P}=\mathrm{t}$} \\
\hline & $\mathrm{T} 1$ & $\mathrm{~T} 2$ & $\mathrm{~T} 3$ & & & \\
\hline \multicolumn{7}{|l|}{ Matéria mineral } \\
\hline $\begin{array}{l}\text { Consumido, } \mathrm{g} / \mathrm{d} \\
\text { Intake }\end{array}$ & $77,38 \mathrm{a}$ & $76,14 \mathrm{a}$ & $70,78 \mathrm{~b}$ & 1,46 & 0,003 & 0,01 \\
\hline $\begin{array}{l}\text { Excretado, } \mathrm{g} / \mathrm{d} \\
\text { Excreted }\end{array}$ & $39,68 \mathrm{a}$ & $35,83 \mathrm{~b}$ & $35,85 \mathrm{~b}$ & 1,67 & 0,09 & 0,11 \\
\hline $\begin{array}{l}\text { Relação excretado:consumido, } \% \\
\text { Excreted:intake ratio } \\
\text { Fósforo }\end{array}$ & 50,99 & 47,08 & 50,71 & 1,97 & 0,31 & \\
\hline $\begin{array}{l}\text { Phosphorus } \\
\text { Consumido, g/d } \\
\text { Intake }\end{array}$ & $8,18 \mathrm{a}$ & $8,05 \mathrm{a}$ & $7,48 b$ & 0,15 & 0,003 & 0,01 \\
\hline $\begin{array}{l}\text { Excretado, g/d } \\
\text { Excreted }\end{array}$ & $5,74 \mathrm{a}$ & $5,18 \mathrm{~b}$ & $5,14 \mathrm{~b}$ & 0,25 & 0,09 & 0,11 \\
\hline $\begin{array}{l}\text { Relação excretado:consumido, } \% \\
\text { Excreted:intake ratio } \\
\text { Nitrogênio }\end{array}$ & 69,93 & 64,39 & 69,01 & 2,90 & 0,36 & \\
\hline $\begin{array}{l}\text { Nitrogen } \\
\text { Consumido, } \mathrm{g} / \mathrm{d} \\
\text { Intake }\end{array}$ & $39,26 \mathrm{a}$ & $38,63 \mathrm{a}$ & $35,91 \mathrm{~b}$ & 0,74 & 0,003 & 0,01 \\
\hline $\begin{array}{l}\text { Fezes excretada, } \mathrm{g} / \mathrm{d} \\
\text { Excreted feces }\end{array}$ & $5,72 \mathrm{a}$ & $5,20 \mathrm{ab}$ & $5,01 \mathrm{~b}$ & 0,31 & 0,13 & 0,11 \\
\hline $\begin{array}{l}\text { Excretado na urina, } \mathrm{g} / \mathrm{d} \\
\text { Excreted urine }\end{array}$ & 15,58 & 15,26 & 14,35 & 0,60 & 0,33 & \\
\hline $\begin{array}{l}\text { Total de nitrogênio excretado, g/d } \\
\text { Total nitrogen excreted }\end{array}$ & $21,30 \mathrm{a}$ & $20,46 \mathrm{ab}$ & $19,35 \mathrm{~b}$ & 0,72 & 0,09 & 0,06 \\
\hline $\begin{array}{l}\text { Relação excretado:consumido, \% } \\
\text { Excreted:intake ratio } \\
\text { Cálcio }\end{array}$ & 54,24 & 53,01 & 53,98 & 1,36 & 0,80 & \\
\hline $\begin{array}{l}\text { Calcium } \\
\text { Consumido, } \mathrm{g} / \mathrm{d} \\
\text { Intake }\end{array}$ & $12,92 \mathrm{a}$ & $12,72 \mathrm{a}$ & $11,82 \mathrm{~b}$ & 0,24 & 0,003 & 0,01 \\
\hline $\begin{array}{l}\text { Excretado, } \mathrm{g} / \mathrm{d} \\
\text { Excreted }\end{array}$ & 8,49 a & $7,46 \mathrm{~b}$ & $7,58 \mathrm{ab}$ & 0,37 & 0,05 & 0,05 \\
\hline $\begin{array}{l}\text { Relação excretado: consumido, } \% \\
\text { Excreted:intake ratio } \\
\text { Magnésio } \\
\text { Magnesium }\end{array}$ & $65,60 \mathrm{a}$ & $58,75 \mathrm{~b}$ & $64,06 \mathrm{ab}$ & 2,65 & 0,09 & 0,01 \\
\hline $\begin{array}{l}\text { Consumido, } \mathrm{g} / \mathrm{d} \\
\text { Intake }\end{array}$ & $2,31 \mathrm{a}$ & $2,27 \mathrm{a}$ & $2,11 \mathrm{~b}$ & 0,04 & 0,004 & 0,003 \\
\hline $\begin{array}{l}\text { Excretado, } \mathrm{g} / \mathrm{d} \\
\text { Excreted }\end{array}$ & 1,47 & 1,45 & 1,37 & 0,11 & 0,81 & \\
\hline $\begin{array}{l}\text { Relação excretado: consumido, \% } \\
\text { Excreted:intake relation }\end{array}$ & 63,77 & 63,77 & 64,67 & 4,98 & 0,99 & \\
\hline $\begin{array}{l}\text { Sódio } \\
\text { Sodium }\end{array}$ & & & & & & \\
\hline $\begin{array}{l}\text { Consumido, } \mathrm{g} / \mathrm{d} \\
\text { Intake }\end{array}$ & $0,82 \mathrm{a}$ & $0,80 \mathrm{a}$ & $0,75 \mathrm{~b}$ & 0,02 & 0,003 & 0,01 \\
\hline $\begin{array}{l}\text { Excretado, g/d } \\
\text { Excreted }\end{array}$ & $0,28 \mathrm{a}$ & $0,31 \mathrm{ab}$ & $0,36 \mathrm{~b}$ & 0,03 & 0,09 & 0,07 \\
\hline $\begin{array}{l}\text { Relação excretado: consumido, \% } \\
\text { Excreted:intake ratio } \\
\text { Potássio }\end{array}$ & $33,31 \mathrm{a}$ & $38,44 \mathrm{a}$ & $48,38 \mathrm{~b}$ & 3,84 & 0,01 & 0,07 \\
\hline $\begin{array}{l}\text { Potassium } \\
\text { Consumido, } \mathrm{g} / \mathrm{d} \\
\text { Intake }\end{array}$ & $11,29 a$ & $11,11 \mathrm{a}$ & $10,32 \mathrm{~b}$ & 0,21 & 0,003 & 0,01 \\
\hline $\begin{array}{l}\text { Relação excretado: consumido, \% } \\
\text { Excreted:intake relation }\end{array}$ & 28,49 & 27,52 & 25,79 & 1,68 & 0,52 & \\
\hline
\end{tabular}

a,b,c Médias na mesma linha, seguidas por letras diferentes, diferem $(P<0,15)$ pelo $F$.

EPM Erro-padrão da média.

a,b,c Means, whithin a row, followed by different letters, are different $(P<.15)$ by $F$ test.

EPM Standard error of mean. 
Tabela 5 - Efeito da restrição alimentar sobre os valores médios de consumo, excreção e a relação excretado:consumido de cobre, ferro, manganês e zinco, na matéria seca

Table 5 - Effect of feed restriction on averages of consumption, excretion and relation excreted:intake of copper, iron, manganese and zinc, in dry matter

\begin{tabular}{|c|c|c|c|c|c|c|}
\hline \multirow{2}{*}{$\begin{array}{l}\text { Parâmetro } \\
\text { Parameter }\end{array}$} & \multicolumn{3}{|c|}{$\begin{array}{c}\text { Tratamento } \\
\text { Treatment }\end{array}$} & \multirow[b]{2}{*}{ EPM } & \multirow[b]{2}{*}{$\mathrm{P}=\mathrm{F}$} & \multirow[b]{2}{*}{$\mathrm{P}=\mathrm{t}$} \\
\hline & $\mathrm{T} 1$ & $\mathrm{~T} 2$ & $\mathrm{~T} 3$ & & & \\
\hline \multicolumn{7}{|l|}{ Cobre } \\
\hline $\begin{array}{l}\text { Copper } \\
\text { Consumido, } \mathrm{mg} / \mathrm{kg} / \mathrm{d} \\
\text { Intake }\end{array}$ & $12,19 \mathrm{a}$ & 11,99 a & $11,15 b$ & 0,02 & 0,003 & \multirow[t]{3}{*}{0,01} \\
\hline Excretado, $\mathrm{mg} / \mathrm{kg} / \mathrm{d}$ & 12,01 & 10,39 & 10,97 & 0,09 & 0,43 & \\
\hline $\begin{array}{l}\text { Excreted } \\
\text { Relação excretado:consumido, \% } \\
\text { Excreted:intake ratio }\end{array}$ & 96,91 & 86,60 & 98,41 & 7,64 & 0,44 & \\
\hline \multicolumn{7}{|l|}{ Ferro } \\
\hline $\begin{array}{l}\text { Iron } \\
\text { Consumido, } \mathrm{mg} / \mathrm{kg} / \mathrm{d} \\
\text { Intake }\end{array}$ & $473,60 \mathrm{a}$ & 466,01 a & $433,17 b$ & 8,91 & 0,003 & \multirow[t]{3}{*}{0,01} \\
\hline $\begin{array}{l}\text { Excretado, } \mathrm{mg} / \mathrm{kg} / \mathrm{d} \\
\text { Excreted }\end{array}$ & 468,56 & 410,18 & 414,40 & 39,18 & 0,51 & \\
\hline $\begin{array}{l}\text { Relação excretado:consumido, \% } \\
\text { Excreted:intake ratio }\end{array}$ & 97,55 & 88,09 & 95,87 & 8,04 & 0,68 & \\
\hline \multicolumn{7}{|l|}{ Manganês } \\
\hline $\begin{array}{l}\text { Manganese } \\
\text { Consumido, } \mathrm{mg} / \mathrm{kg} / \mathrm{d} \\
\text { Intake }\end{array}$ & $31,43 \mathrm{a}$ & $30,29 a$ & $28,74 b$ & 0,59 & 0,003 & \multirow[t]{3}{*}{0,01} \\
\hline $\begin{array}{l}\text { Excretado, mg/kg/d } \\
\text { Excreted }\end{array}$ & 30,64 & 28,78 & 28,05 & 1,44 & 0,43 & \\
\hline $\begin{array}{l}\text { Relação excretado:consumido, \% } \\
\text { Excreted:intake relation }\end{array}$ & 96,36 & 93,10 & 97,67 & 4,15 & 0,73 & \\
\hline \multicolumn{7}{|l|}{ Zinco } \\
\hline $\begin{array}{l}\text { Zinc } \\
\text { Consumido, } \mathrm{mg} / \mathrm{kg} / \mathrm{d} \\
\text { Intake }\end{array}$ & $206,23 \mathrm{a}$ & 202,93 a & $188,63 \mathrm{~b}$ & 3,88 & 0,003 & \multirow[t]{3}{*}{0,01} \\
\hline $\begin{array}{l}\text { Excretado, } \mathrm{mg} / \mathrm{kg} / \mathrm{d} \\
\text { Excreted }\end{array}$ & 194,96 & 179,94 & 180,70 & 7,78 & 0,32 & \\
\hline $\begin{array}{l}\text { Relação excretado:consumido, } \% \\
\text { Excreted:intake relation }\end{array}$ & 93,74 & 88,70 & 95,81 & 3,34 & 0,31 & \\
\hline $\begin{array}{ll}\text { a,b,c } & \text { Médias na mesma linha, seguid } \\
\text { EPM } & \text { Erro-padrão da média. } \\
\text { a,b,c } & \text { Means whithin a row, followed by dit } \\
\text { EPM } & \text { Standard error of mean. }\end{array}$ & letters, & ent $(P<.15)$ & $\begin{array}{l}(\mathrm{P}<0,15) \\
\text { test. }\end{array}$ & & & \\
\hline
\end{tabular}

nitrogênio, conforme descrito por Lenis (1989) e Belli Filho (1995). Verificou-se que $13,98 \%$ do $\mathrm{N}$ ingerido foram excretados nas fezes e 39,69\%, na urina. Estes valores estão abaixo dos observados por Belli Filho (1995), que conclui que um suíno excreta $20 \%$ do $\mathrm{N}$ ingerido nas fezes e $50 \%$ na urina.

As relações das quantidades de $\mathrm{P}$ e $\mathrm{N}$ excretados sobre as quantidades consumidas desses elementos não foram diferentes entre os tratamentos, indicando que o grau de aproveitamento pelos animais não variou em função da quantidade oferecida. Bridges et al. (1995) observaram que a relação excretado: consumido destes minerais foi de $61 \%$, em média, resultado semelhante ao deste experimento, que foi, em média, de $67,78 \%$.

A redução de $8,54 \%$ (T3) no consumo diário acarretou excreção de $9,65 \%$ a menos de matéria mineral nas fezes quando comparado ao consumo ad libtum ( $\mathrm{P}=0,11)$. Segundo Honeyman (1992), a composição da dieta ingerida pelos suínos apresenta grande influência na qualidade das fezes excretadas. Neste estudo, a relação matéria mineral excretada: consumida foi similar $(\mathrm{P}=0,31)$ entre os tratamentos. 
$\mathrm{O} \mathrm{Mg}$ foi o único macromineral que não sofreu redução significativa $(\mathrm{P}=0,81)$ no conteúdo fecal com o aumento da restrição alimentar. Por outro lado, o conteúdo de sódio nas fezes foi maior nos animais do T3 que naqueles que receberam ração à vontade $(\mathrm{P}=0,07)$, o que é de difícil explicação, uma vez que a maior parte do sódio é excretada pela urina (Kohler et al., 1992), que não foi analisada. Entretanto, uma das funções do sódio é participar no transporte ativo secundário, na absorção de vários nutrientes no intestino (Vander et al., 1980). Como neste caso a restrição alimentar reduziu a quantidade de nutrientes reabsorvidos, mais sódio foi encontrado nas fezes.

Similarmente ao ocorrido com a matéria mineral fecal, também os teores de $\mathrm{Ca}$ e $\mathrm{P}$ das fezes dos animais que sofreram restrição alimentar foram reduzidos significativamente $(\mathrm{P}=0,05$ e $\mathrm{P}=0,04$, respectivamente $)$.

A restrição alimentar não afetou $(\mathrm{P}=0,51)$ a quantidade de $\mathrm{Cu}, \mathrm{Fe}, \mathrm{Mn}$ e $\mathrm{Zn}$ nas fezes dos animais (Tabela 5). Entretanto, para todos os microminerais, as relações entre as quantidades excretadas e as quantidades consumidas foram iguais ou superiores a $86,60 \%$, indicando que os animais apresentam baixa eficiência de retenção de microminerais. Esses valores sugerem uma preocupação adicional quanto ao potencial poluente do $\mathrm{Cu}$ e $\mathrm{Zn}$, principalmente porque esses minerais são utilizados em altas dosagens como promotor de crescimento ( $\mathrm{Cu}$ e $\mathrm{Zn}$ ) e no controle da diarréia (Zn). Adeola et al. (1995) observaram que as relações excretado:consumido de $\mathrm{Mn}, \mathrm{Cu}$ e $\mathrm{Zn}$ foram, respectivamente, 50,63, 77,30 e 69,65\% para suínos com 9,4 kg. Poulsen \& Larsen (1995), estudando suínos com $35 \mathrm{~kg}$ de peso vivo, verificaram relação de $80,85 \%$ de $\mathrm{Zn}$ excretado:consumido quando os animais receberam dieta com $42 \mathrm{mg} / \mathrm{kg}$ de $\mathrm{Zn}$, na matéria seca, provenientes do óxido de zinco. Este valor foi menor que o encontrado neste experimento, que foi de $93,73 \%$ de $\mathrm{Zn}$ quando os animais receberam ração à vontade contendo $126,06 \mathrm{mg} / \mathrm{kg}$ de $\mathrm{Zn}$, na matéria seca.

\section{Conclusões}

A restrição alimentar de suínos em crescimento acarreta redução da quantidade de matéria seca excretada, bem como da fração matéria mineral e da maioria dos minerais estudados.

O uso da técnica de restrição alimentar em suínos na fase de crescimento constitui-se prática eficiente de redução da quantidade de fezes e de minerais excretados, reduzindo o potencial poluente dos dejetos suínos.

\section{Agradecimento}

Ao CNPq e à Embrapa Suínos e Aves.

Literatura Citada

ADEOLA, O.; LAWRENCE, B.V.; SUTTON, A.L. et al. Phytase-induced changes in mineral utilization in zincsupplemented diets for pigs. Journal Animal Science, v.73, p.3384-3391, 1995

ANDERSON, M.; BAEKBO, P.; NIELSEN, K. The effect of aerial ammonia on the MIRD complex. In: INTERNATIONAL CONGRESS PIG VETERINARY SOCIETY, 13., 1994, Bangkok. Proceedings... Bangkok: IPVS, 1994. p.429.

BELLAVER, C. Restrição da alimentação para suínos. Suinocultura dinâmica. Concórdia: EMBRAPA-CNPSA. Ano I, N 2. abril 1992, p.1-3.

BELLI FILHO, P. Stockage et odeurs des dejections animales cas du lisier de porc. Rennes-France: U.F.R. Ëcole Nationale Supériore de Chimie, 1995. 232p. Thése Docteur - U.F.R. Ëcole Nationale Supériore de Chimie Rennes, 1995.

BOHRER, P.H.A suinocultura brasileira. In: CONGRESSO BRASILEIRO DE VETERINÁRIOS ESPECIALISTAS EM SUÍNOS, 11., 2003, Goiânia. Anais... Goiânia: ABRAVES, 2003. p.46-64.

BRIDGES, T.C.; TURNER, L.W.; CROMWELL, G.L. et al. Modeling the effects of diet formulation on nitrogen and phosphorus excretion in swine waste. Applied Engineering in Agriculture, v.11, n.5, p.731-739, 1995.

BROWN, J.A.; CLINE, T.R. Urea excretion in the pig: an indicator of protein quality and amino acid requeriments. Journal Nutrición, n.104, p.542-545, 1974.

CAMPBELL, R.G.; KING, R.H. The influence of dietary protein and level of feeding on the growth performance and carcass characteristics od entire and castrated male pigs. Animal Produccin, v.35, p.177-184, 1982.

CLANTON, C.J.; NICHOLS, D.A.; MOSER, R.L. Swine manure characterization as affected by environmental temperature, dietary level intake, and dietary fat addition. Transactions of the ASAE, v.34, n.5, p.2164-2170, 1991.

COLE, D.J.A.; SCHURINK, G.; KONING, W.J. Ammonia on pig buildings in the Netherlands. Pig News and Information, v. 17, n. 2, p.53N-56N, 1996.

CROMWELL, G.L.; CARTER, S.D.; LINDERMANN, M.D. et al. Reducing the excretion of nitrogen and phosphorus in growing and finishing pigs by dietary manipulation. In: INTERNATIONAL CONGRESS PIG VETERINARY SOCIETY, 14.,1996, Bologna. Proceeding.... Bologna: IPVS, 1996. p.418.

GUIVANT, J. Atores e arenas na formação de uma rede para o controle da poluição agrícola em condições de competitividade globalizada. In: ENCONTRO ANUAL DA ASSOCIAÇÃO NACIONAL DE PÓSGRADUÁÇÃO E PESQUISA EM CIÊNCIAS SOCIAIS, ECOLOGIA E SOCIEDADE, 20., 1996, Caxambu. Anais... Caxambu: Associação Nacional de Pós-Graduação e Pesquisa em Ciências Sociais, Ecologia e Sociedade, 1996. p.3-34.

HENRY, Y.; DOURMAND, J.Y. Protein nutrition and nitrogen pollution. Feed mix: the international journal on feed, nutrition and technology, v.1, n.1, p.25-28, 1992. 
HONEYMAN, M.S. Waste manegement in pig units: The challenge and the opportunity in the U.S. In : ALTECH'S ANNUAL SYMPOSIUM BIOTECHINOLOGY IN THE FEED INDUSTRY, 11., 1992, Kentucky. Proceedings... Kentucky: Alltech Techinical, 1992. p.251-259.

INBORR, J. How feed enzymes can reduces manure problems. Pig International, v.22, n.1, p.21-22, 1992.

KOHLER, T.; VERSTEGEN, M.W.A.; MOSENTHIN, R. et al. Effect ileo-rectal anasyomosis and post-valve T-caecum cannulation on growing pigs. Britsh Journal of Nutrición, v.68, p.305-315, 1992.

KOLB, E. Fisiologia veterinária. 2.ed. Zaragosa: Acribia, 1976. v.1, p.569.

LATIMIER, P.; DOURMAD, J.Y. Effect of three protein feeding strategies, for growing-finishing pigs, on growth performance and nitrogen output in the slurry and in the air. In: INTERNATIONAL CONGRESS ON NITROGEN FLOW IN PIGS, 1993, Wageningen. Proceedings... Wageningen: 1993. p.439.

LENIS, N.P. Lower nitrogen excretion in pig husbandry by feeding: current and future possibilities. Netherlands Journal of Agricultural Science, v.37, p.61-70, 1989.

LEYMASTER, K.A.; MERSMANN, H.J. Effect of limited feed intake on growth of subcutaneous adipose tissue layers and on carcass composition in swine. Journal of Animal Science, v.69, p.2837-2843, 1991.

NATIONAL RESEARCH COUNCIL - NRC. Nutrients requirement of swine. 10.ed. Washington, D.C.: 1998. 189p.

OLIVEIRA, P.A.V.; MARTINS, R.R.; PEDROSO, D. et al. Manual de manejo e utilização dos dejetos de suínos. 1.ed. Concórdia: EMBRAPA-CNPSA, 1993. 188p. (Documentos, 27)

OLIVEIRA, P.A. Manejo da água e detalhes construtivos Influência no volume de dejtos produzidos. In: DIA DE CAMPO SOBRE MANEJO E UTILIZAÇÃO DE DEJETOS. 1., 1994, Concórdia. Anais.... Concórdia: CNPSAEMBRAPA, 1994. p.25-28.
PERDOMO, C. Uso racional dos dejetos de suínos. In: SEMINÁRIO INTERNACIONAL DE SUINOCULTURA, 1., 1996, São Paulo. Anais... São Paulo, 1996. p.269.

POULSEN, H.D.; LARSEN, T. Zinc excretion and retention in growing pigs feed increasing levels of zinc oxide. Livestock Production Science, v.43, n.3, p.235-242, 1995.

QUINIOU, N.; NOBLET, J.; DOURMAD, J.Y. Influence et d'une réduction du taux proteique du régime sur les réjets d'azote et de phospore chez le porc. Journal Recherche Porcine en France, v.25, p.287-294, 1994.

QUINIOU, N.; DUBOIS, S.; NOBLET, J. Effect of dietary crude protein level on protein and energy balances in growing pigs: comparison of two measurement methods. Livestock Producción Science, v.41, p.51-61, 1995.

STATISTICAL ANALYSES SYSTEM - SAS. System for Microsoft Windows. Release 8.2, Cary: 2001. CD ROM.

SILVA, D.J. Análise de alimentos: métodos químicos e biológicos. 1.ed. Viçosa, MG: Universidade Federal de Viçosa, 1990. 160p.

SILVA, C.A.; FREITAS, J.C.; ALFRIERI, A.A. et al. Ocorrência de E coli, Rotavirus e Cryptosporidium parvum em um surto de diarréia pó-desmame. In: CONGRESSO BRASILEIRO DE VETERINÁRIOS ESPECIALISTAS EM SUÍNOS, 6., 1993, Goiânia. Anais... Goiânia: ABRAVES, 1993. p.82.

VANDER, J.A.; SHERMAN, J.H.; LUCIANO, D.S. Fisiologia humana. São Paulo: Mc Graw Hill do Brasil, 1980. p.831.

VOOLBURG, J.H. The utilization of animal manure with protection of the environment. Institute of Agricultural engineering IMAG-DLO. Wageningen: 1991. 41p.

Recebido em: 26/04/04

Aceito em: $17 / 11 / 04$ 